\title{
Dişlisiz Asansör Uygulamaları için Yüzey Montajlı Senkron Motorun Optimal Tasarımı
}

\author{
Musab OKŞAR ${ }^{1}$, Hicret YETIŞ⿻ి ${ }^{2}$ Taner GÖKTAŞ ${ }^{3^{*}}$, Asım KAYGUSUZ ${ }^{4}$, Erkan MEŞE $^{5}$ \\ 1,2,3,4 Elektrik-Elektronik Mühendisliği, Mühendislik Fakültesi, İnönü Üniversitesi, Malatya, Türkiye \\ ${ }^{5}$ Elektrik-Elektronik Mühendisliği, Mühendislik Fakültesi, Ege Üniversitesi, İzmir, Türkiye \\ ${ }^{1}$ musab.oksar@inonu.edu.tr, ${ }^{2}$ hicretyetis@gmail.com, ${ }^{* 3}$ taner.goktas@inonu.edu.tr, ${ }^{4}$ asim.kaygusuz@inonu.edu.tr, \\ 5 erkan.mese@ege.edu.tr
}

\begin{abstract}
Öz: Mıknatıslı Senkron Makineler tarafından sürülen dişlisiz asansör sistemleri, geleneksel asenkron motor uygulamalarına kıyasla yüksek verim, yüksek moment yoğunluğu, dişli kutusunun ortadan kalkması ile kayıpların azalması ve sistemin hacminin küçülmesi gibi birçok avantaja sahiptir. Bu çalışmada $800 \mathrm{~kg} / 10$ kişilik taşıma kapasitesine sahip bir dişlisiz asansör sistemini sürmek için tasarlanan 27-oluklu 30-kutuplu Yüzey Montajlı Senkron Motorun (YMSM) tasarımı yapılmıştır. Tasarım süreci içerisinde kritik önem teşkil eden; hava aralığı, oluk açıklığı ve mıknatıs kalınlığı gibi geometrik boyutlar parametrik analiz ve çok amaçlı optimizasyon yöntemi kullanılarak belirlenmiştir. Optimizasyon süreci sonucunda elde edilen motor; verim, akı dağılımı, çıkış ve vuruntu momenti açısından analiz edilmiştir. Enerji verimliliği ve performans açısından optimal bir tasarım hedeflenmiş̧tir. Yapılan tasarım ve analizler ANSYS@Maxwell simülasyon programı kullanılarak gerçekleştirilmiştir.
\end{abstract}

Anahtar kelimeler: Çok amaçlı optimizasyon, Doğrudan sürüşlü sistemler, Genetik algoritma, Parametrik analiz, Yüzey montajli senkron motor.

\section{Optimal Design of Surface Mounted Synchronous Motors for Gearless Elevator Systems}

\begin{abstract}
Gearless elevator systems driven by Magnet Synchronous Machines have many advantages compared to conventional asynchronous motor applications such as high efficiency, high torque density, reduction of losses caused by gear box reduction and volume reduction of the system. In this study, the design stages of with 27-slot / 30-pole Surface Mounted Synchronous Motor (SPM) designed to drive a gearless elevator system with a carrying capacity of $800 \mathrm{~kg} / 10$ people are described. Critical in the design process; geometric dimensions such as air gap, slot opening and magnet thickness were determined using parametric analysis and multi-objective optimization method. The motor obtained as a result of the optimization process; efficiency, flux distribution, output torque and cogging torque value were analyzed. An optimal design has been tried to be achieved in terms of energy efficiency and performance. Design and analysis were performed using ANSYS@ Maxwell simulation program.
\end{abstract}

Key words: Multi-objective optimization, Direct drive applications, Genetic algorithm, Parametric analysis, Surface mounted synchronous motors.

\section{Giriş}

Elektrik enerjisini verimli şekilde kullanabilmek için asansör sistemlerinde teknik olarak birçok iyileștirici çalışmalar yapılmıştır. Yüksek verimli elektrik motorlarının üretilmesi ile asansörler büyük ve kalabalık şehirlerde modern yaşamın vazgeçilmez parçası haline gelmişlerdir. YMSM'ler, asansör sistemleri gibi düşük hızlı uygulamalarda asenkron motorlara kıyasla daha iyi kontrol imkânı sağladıklarından oldukça iyi performans gösterirler [1-2]. Ayrıca rotorda meydana gelen bakır kayıpları ve dişli kutusunun sebep olduğu kayıplar ortadan kalktığı için enerji verimliliği açısından oldukça iyi motorlardır [3-4]. [5-7] numaralı çalışmalarda; YMSM'lerin, makine ve yük arasındaki dişli kutuları veya diğer mekanik aktarma bileşenlerini ortadan kaldıran doğrudan sürüşlü asansör uygulamaları için oldukça tercih edildiği vurgulanmıştır. Doğrudan sürüşlü uygulamaları ile asansör sistemlerinde son y1llarda oldukça büyük bir gelişme kaydedildiği belirtilmiştir. Geleneksel asansör sistemlerinin standart olarak; asansör şaftının üst kısmında ayrı bir odada bulunan bir asenkron motor, dişli kutusu, kasnak ve kablo kanalından oluştuğu ifade edilmiștir. 1990 yıllarının ortalarında asansör üreticilerinin ayrı bir makine dairesi ihtiyacını ortadan kaldıran YMSM'li sistemleri tanıtarak asansör sistemlerinde sessiz bir devrim yarattıkları belirtilmiştir. YMSM'ler makine dairesi ve dişli kutusu ihtiyacını ortadan kaldırılması, iyi sürüş konforu, yüksek verimlilik, zayıflatılmış mekanik gürültü ve doğrudan sürüş imkânı ile gibi üstün özelliklerinden dolayı asansör sistemleri için oldukça talep gören motorlar arasında yerini almışlardır [8-11].

\footnotetext{
* Sorumlu yazar: taner.goktas@ @inonu.edu.tr. Yazarların ORCID Numarası: ${ }^{10000-0002-0680-2421, ~}{ }^{20000-0002-3173-5611,}{ }^{3} 30000-0002-$ $8218-3239,{ }^{4} 0000-0003-2905-1816,{ }^{5} 0000-0002-6305-1281$
} 
Tablo 1. YMSM'ye ait tasarım özellikleri

\begin{tabular}{|c|c|}
\hline Tasarım Parametreleri & Değer (Birim) \\
\hline Nominal güç & $8.8 \mathrm{~kW}$ \\
\hline Nominal hız & $255 \mathrm{~d} / \mathrm{d}$ \\
\hline Çıkış momenti & $330 \mathrm{Nm}$ \\
\hline Uygulanan gerilim & $380 \mathrm{~V}$ \\
\hline Oluk sayısı & 27 \\
\hline Kutup sayıs1 & 30 \\
\hline Aktif uzunluk & $85 \mathrm{~mm}$ \\
\hline Stator burulma faktörü ( Skew width) & 0.2 \\
\hline Sargı tipi & Konsantre \\
\hline Stator oluklarındaki iletken sayısı & 104 \\
\hline Armatür akım yoğunluğu & $5.7 \mathrm{~A} / \mathrm{mm}^{2}$ \\
\hline PM materyali & NdFe35 \\
\hline Stator ve rotor çelik materyali & 1008 \\
\hline
\end{tabular}

Bu çalışmada $800 \mathrm{~kg} / 10$ kişilik taşıma kapasitesine sahip dişlisiz asansör sistemi için $8.8 \mathrm{~kW}$ gücünde ve $330 \mathrm{Nm}$ moment üreten bir YMSM tasarımı gerçekleştirilmiştir. Motorun ana geometrisi dişlisiz asansör uygulamaların da talep edilen boyutlara uygun olarak belirlenmiştir. Diğer geometrik boyutlar [10] numaralı çalışmada sunulan motor performansı üzerinde etkili olan kritik boyutların parametrik analiz ile belirlenmesi yönteminden yararlanılarak ANSYS@Maxwell programının RMxprt bölümünde bulunan parametrik analiz ve çok amaçlı optimizasyon yöntemleri kullanılarak tayin edilmiştir. Tasarım sürecinde parametrik analizler yapılarak hava aralığı, mıknatıs kalınlığı, mıknatıs doluluk oranı, oluk açıklığı ve oluk uzunluğu değerlerinin; verim, çıkış momenti, vuruntu momenti ve stator dişlerindeki akı yoğunluğu üzerindeki etkisi araştırılmıştır. Çok amaçlı optimizasyon yöntemi kullanılarak belirtilen parametrelerin optimum olduğu noktalar, optimizasyon algoritması vasıtası ile seçilerek performans açısından iyi bir tasarım elde edilmiştir.

\section{YMSM Tasarımı}

"Asansör sistemlerinde Avrupa Standartlarına (Elevator EN Standards)" uygun olarak her kişi 75-80 kg olarak kabul edilirse 10 kişilik asansör sisteminin taşıma kapasitesi $800 \mathrm{~kg}$ olarak belirlenir [13]. Bu taşıma kapasitesine sahip dişlisiz asansör sistemi için tasarlanacak olan senkron motorun moment, hız ve güç parametreleri endüstride kullanılan asansör sistemlerine uygun olarak sırası ile; $330 \mathrm{Nm}, 8.8 \mathrm{~kW}$ ve $255 \mathrm{~d} / \mathrm{d}$ olarak belirlenmiştir. Motorun ana geometrisi; belirlenen hız ve moment değerine sahip motorlar için endüstriyel olarak asansör uygulamalarında $800 \mathrm{~kg}$ taşıma kapasiteli sistemler için talep edilen boyutlar doğrultusunda seçilmiştir. Tasarlanan YMSM'nin özellikleri Tablo 1'de özetlemiştir.

\subsection{Parametrik analiz}

Parametrik analiz, ANSYS@Maxwell programının RMxprt bölümünde bulunan, her bir giriş parametresinin belirli aralıkta ve belirli adım sayısında değiştirilerek analiz edilmek istenen çıkış değerleri üzerindeki etkisinin gözlemlendiği bir analiz tekniğidir. Bu yöntem ile performans açısından önem teşkil eden verim, moment ve akı yoğunluğu gibi çıkış değerlerini en optimum şekilde sağlayan giriş parametre değerleri belirlenir. YMSM için dört adet giriş parametresinin dört adet çıkış değeri üzerindeki etkisi incelendiği parametrik analiz adımları Şekil 1'de gösterilmektedir. Şekil 1'de;

$i=1,2, \ldots, k$ tamsayı olmak üzere,

$X_{i}$ : motor giriş parametreleri, (örn; hava aralığı, mıknatıs kalınlığı vs.)

$Y_{i}$ : motor çıkış değerleri (örn; verim, moment vs.), $a_{i}-b_{i}$ : değişkenlerin değer aralıkları,

$\Delta X_{i}$ : değişkenlerin parametrik analizdeki artış miktarları,

$N_{i}$ : belirtilen aralık ve artış miktarına göre değişkenlerin adedi $\left(N_{i}=\frac{b_{i}-a_{i}}{\Delta X_{i}}\right)(\mathrm{N}=$ tamsayı) olarak ifade edilmiştir. 


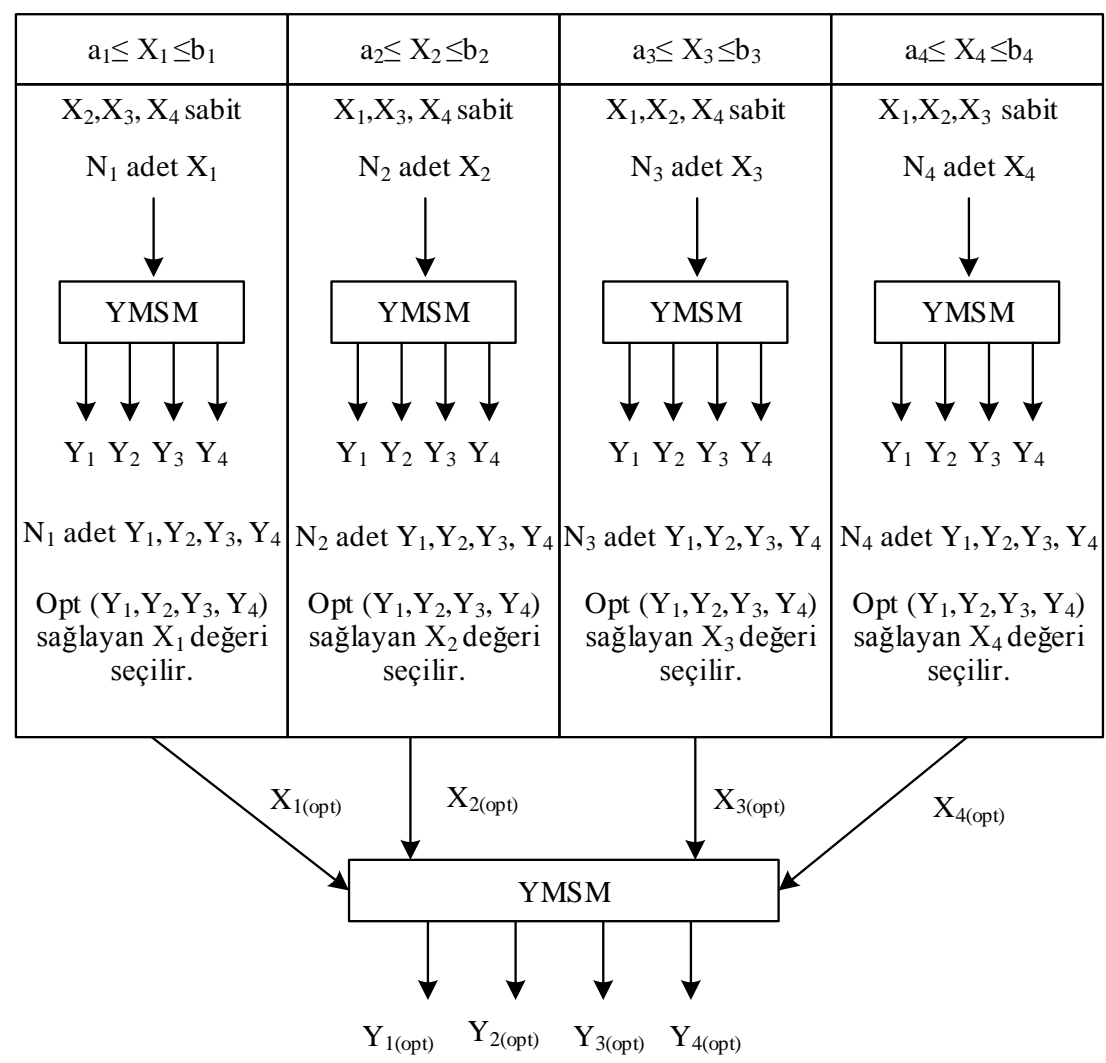

Şekil 1. Parametrik analiz adımları

YMSM tasarımında; hava aralığı, mıknatıs geometrisi ve stator oluk yapısı motor performansı için oldukça önemli olan parametrelerdir [10], [14-19]. Bu nedenle tasarlanan YMSM'nin hava aralığı, mıknatıs kalınlığı, mıknatıs doluluk oranı, oluk açıklığı ve oluk uzunluğu değerlerinin; verim, çıkış momenti, vuruntu momenti ve stator dişlerindeki akı yoğunluğu değerleri üzerindeki etkisi parametrik analizler yapılarak incelenmiştir. Parametrik analizler Tablo 2'de belirlenen değerler doğrultusunda yapılmıştır. Analiz edilen tasarım parametreleri Şekil 2'de gösterilmiş̧ir. Parametrik analiz sonuçları ise Şekil 3 ve Şekil 4 'te gösterilmiştir. Analiz sonuçları incelenerek aşağıdaki sonuçlara ulaşılmıştır.

Hava aralığ $(g)$ azaltıldığında; verim ve stator dişlerindeki akı yoğunluğunun arttığı, vuruntu momenti ve çıkış momentinin lineer olmayan bir değişim sergilediği gözlemlenmiş̧ir. Mıknatıs kalınlığı $(l m)$ arttırıldığında; verim ve stator dişlerindeki akı yoğunluğunun arttı̆ı, vuruntu ve çıkış momentinin lineer olmayan bir değişim sergilediği gözlemlenmiştir. Mıknatıs doluluk oranı (emb) artıııldığında; verim ve stator dişlerindeki akı yoğunluğunun arttığ 1 , vuruntu ve çıkış momentinin lineer olmayan bir değişim sergilediği gözlemlenmiştir. Oluk açıklı̆g 1 (Bs0) arttırıldığında; verimin arttığı, stator dişlerindeki akı yoğunluğunun azaldığı, vuruntu ve çıkış momentinin lineer olmayan bir değişim sergilediği gözlemlenmiş̧tir. Oluk uzunluğu (Hs2) arttırıldığında; verim ve vuruntu momentinin arttığı, stator dişlerindeki akı yoğunluğunun azaldığı, çıkış momentinin lineer olmayan bir değişim sergilediği gözlemlenmiştir.

Tablo 2. Parametrik analiz değişkenleri

\begin{tabular}{|c|c|c|c|}
\hline & Birim & Değer aralıkları & $\operatorname{Artış}(\Delta)$ \\
\hline Hava aralığı (g) & $m m$ & $1<g<2$ & $\Delta_{g}=0.02$ \\
\hline M1knatıs kalınlığı (lm) & $m m$ & $4<\operatorname{lm}<8$ & $\Delta_{l m}=0.1$ \\
\hline Miknatıs doluluk oranı (emb) & - & $0.7<e m b<0.96$ & $\Delta_{e m b}=0.01$ \\
\hline Oluk açıklığı (Bs0) & $m m$ & $3<B s O<8$ & $\Delta_{B s 0}=0.1$ \\
\hline Oluk uzunluğu (Hs2) & $m m$ & $25<H s 2<36$ & $\Delta_{H s 2}=0.4$ \\
\hline
\end{tabular}


Dişlisiz Asansör Uygulamaları için Yüzey Montajlı Senkron Motorun Optimal Tasarımı

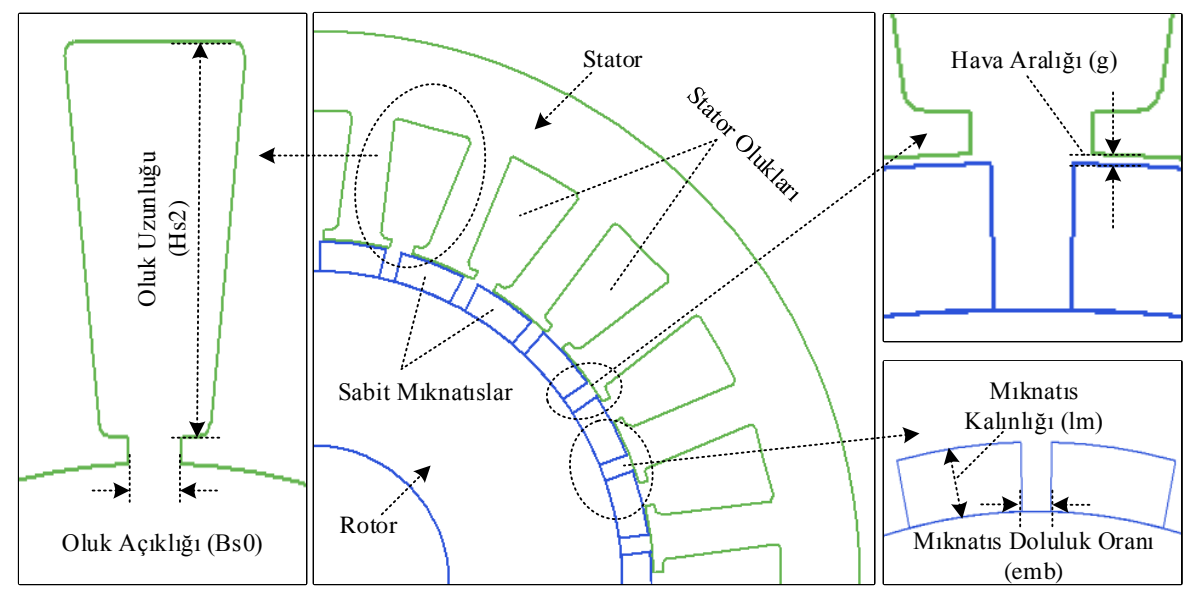

Şekil 2. Analiz edilen tasarım parametreleri

Verim [\%]
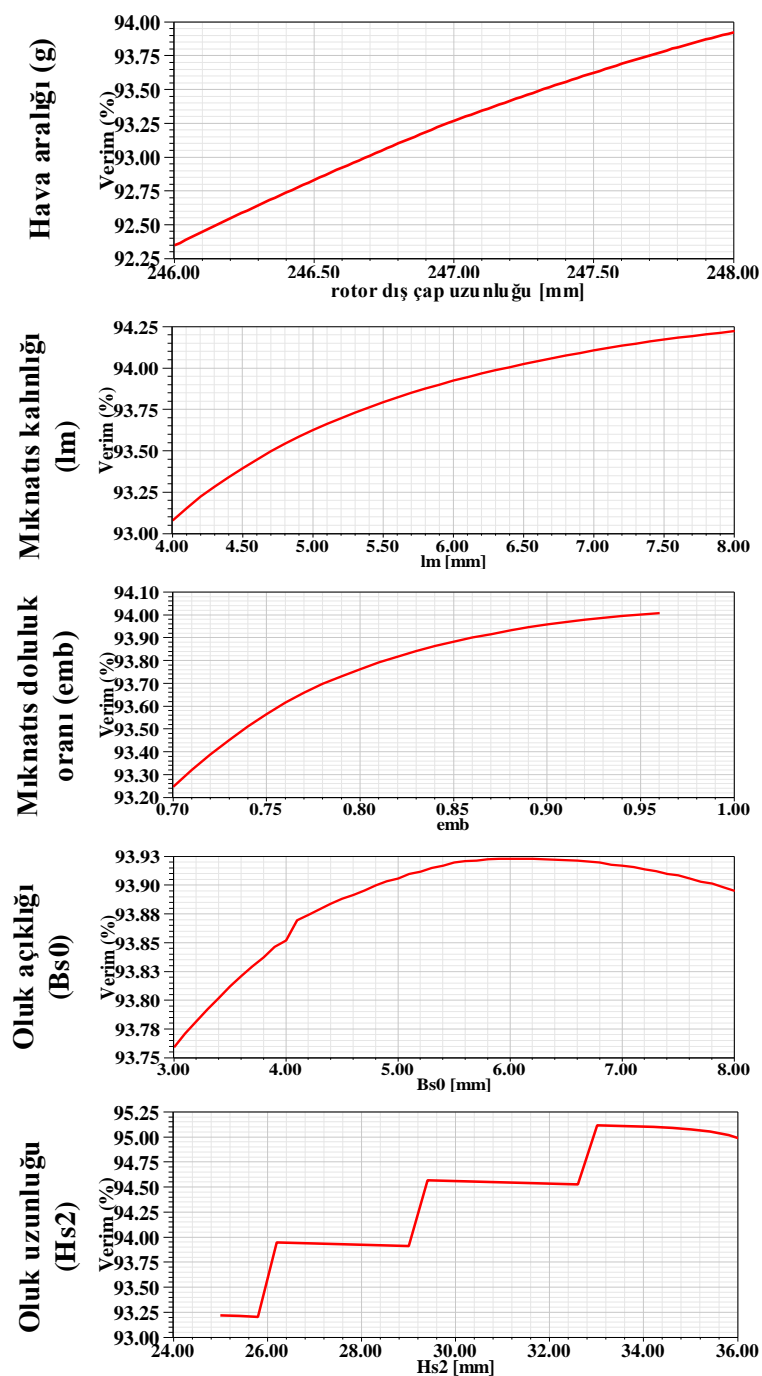

Şekil 3. Parametrik analiz sonuçları (verim ve vuruntu momenti)

Vuruntu Momenti [mNm]
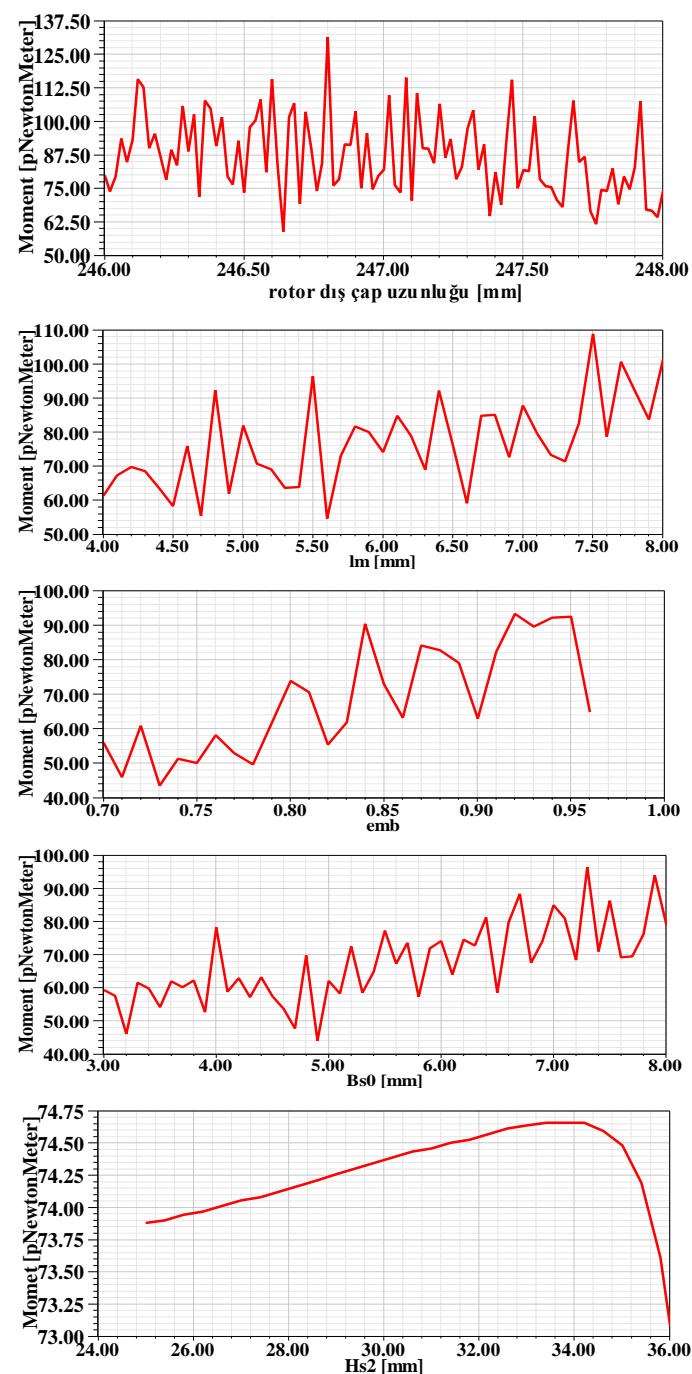
Stator Dişlerindeki Akı Yoğunluğu (T)
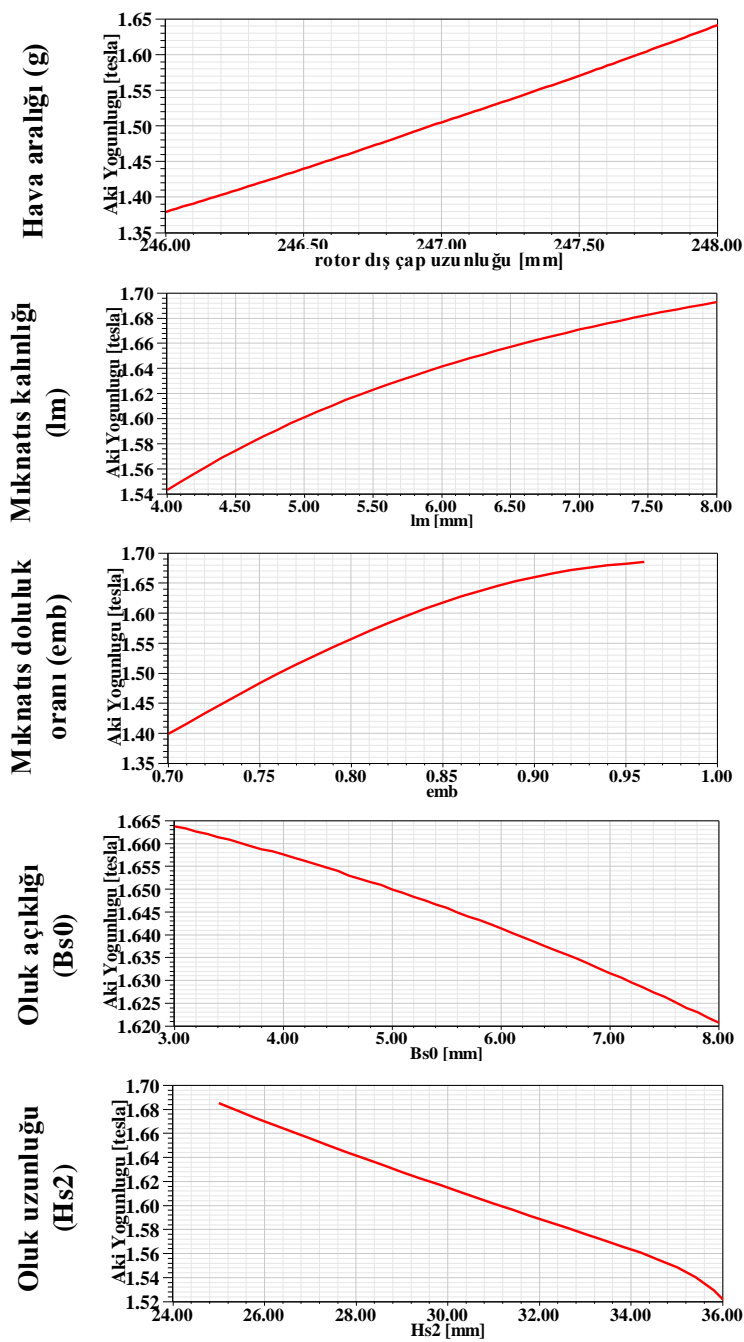

Çıkış Momenti (Nm)
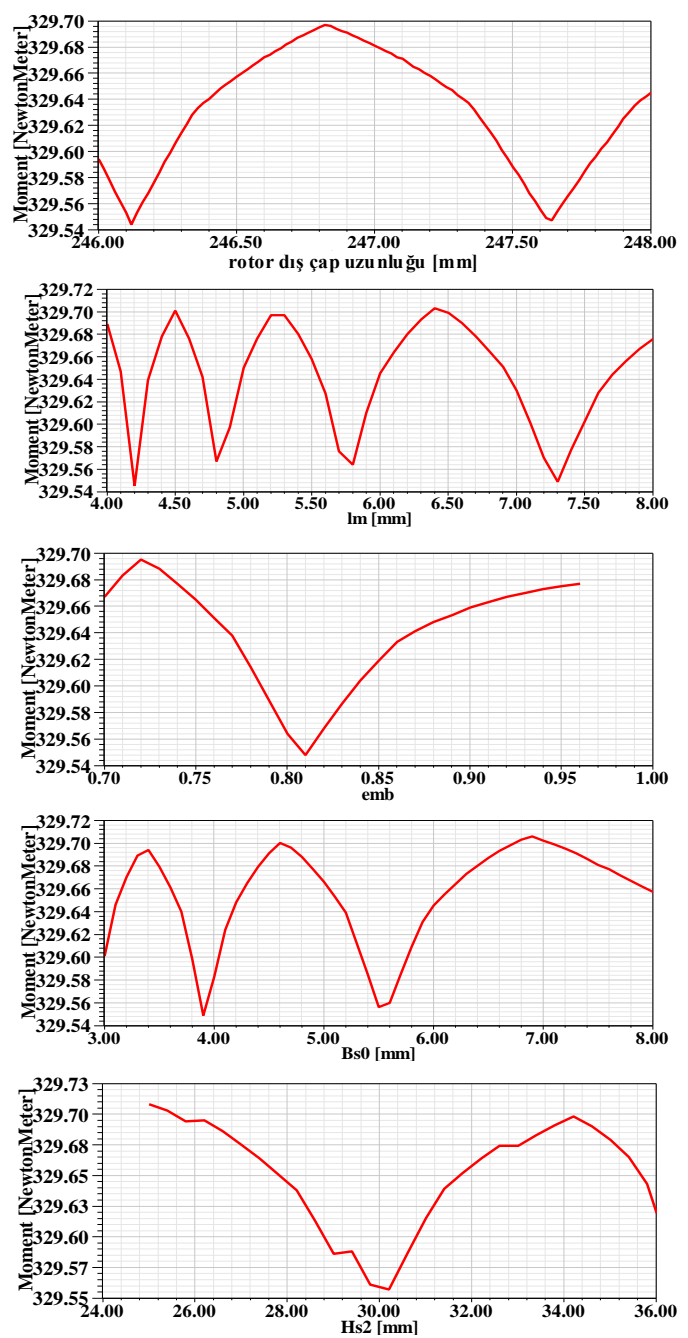

Şekil 4. Parametrik analiz sonuçları (stator dişlerindeki akı yoğunluğu ve çıkış momenti)

Asansör uygulamaları için tasarlanan elektrik motorları performans açısından değerlendirilirken öncelikli olarak önem verilen ölçütler; yüksek verim, düşük vuruntu momenti, stator akı yoğunluğunun 1.8 Tesla'y1 aşmaması ve lineer çıkış momenti (düşük moment dalgalılığı) olarak sıralanır [10], [20-21]. Bu bağlamda parametrik analiz sonuçları incelendiğinde; hava aralığı, mıknatıs geometrisi ve stator oluk yapısı parametrelerin değişiminin performans açısından önemli ölçütler olan verim, vuruntu momenti, akı yoğunluğu ve çıkış moment değerleri üzerinde farklı etkileri olduğu görülmektedir. Örneğin, Şekil 3 ve Şekil 4'te gösterilen; hava aralığ1 değerinin arttırılması motorun performansını; verimi arttırarak olumlu yönde etkilerken vuruntu momenti ve stator dişlerindeki akı yoğunluğunu arttırarak olumsuz yönde etkilemektedir. Ayrıca parametrik analiz yöntemi ile motor giriş parametrelerinin çıkış değerleri üzerindeki etkilerinin incelenebilmesi için; Şekil 1'de ifade edildiği gibi ayrı ayrı adımlarda analiz yapılması gerekmektedir. Bu da her bir analiz sonucunun ayrıca yorumlayıp giriş parametrelerinin optimum olduğu noktaların tasarımcı tarafından seçilmesini zorunlu kılmaktadır. Bu durum tasarımcı açısından parametrelerin optimum olduğu değerlerin seçimini yapmayı güçleştirmektedir. $\mathrm{Bu}$ soruna çözüm olarak; çok amaçlı optimizasyon yöntemi kullanılarak belirtilen parametrelerin optimum olduğu noktaların, optimizasyon algoritması vasıtası ile seçilmesi önerilmiştir.

\section{2. Çok amaçlı optimizasyon}

Optimal YMSM tasarımı sürecinde faydalanılacak olan çok amaçlı optimizasyon; ANSYS@Maxwell programının RMxprt bölümünün “Optimetric Analysis” sekmesi altında bulunan “optimization” çözdürücüsü 
kullanılarak yapılan bir analizdir. Çok amaçlı optimizasyon yöntemi yardımı ile YMSM tasarımı ve optimizasyonu [22-26] numaralı çalışmalarda detaylı olarak anlatılmıştır. Bu çalışmada parametrik analiz yöntemi ile birikte çok amaçlı optimizasyon yöntemi kullanılarak; çıkış değerleri üzerinde etkisi olan giriş parametrelerinin optimum olduğu değerler optimizasyon algoritması tarafından seçilerek, performans açısından olabilecek en iyi tasarıma ulaşmak hedeflenmektedir. Optimal tasarımın için; hava aralığı, mıknatıs doluluk oranı, mıknatıs kalınlığı, stator oluk açıklığı ve stator oluk uzunluğu parametrelerinin değeri, genetik algoritma yöntemi kullanılarak çok amaçlı optimizasyon sonucunda belirlenmiştir.

Genetik algoritma, John H. Holand tarafından ortaya konmuş evrimsel bir optimizasyon yöntemidir [27]. Genetik algoritma ilhamını; doğal seçilim ve genetik biliminden alan bir metasezgisel bir arama algoritmasıdır [28].Genetik algoritma yöntemi; mühendislik uygulamalarında kullanılan gradyan tabanlı klasik optimizasyon yöntemlerine göre lokal optimum noktalarına takılmadan çözüm uzayını global olarak araştırması ve daha hızlı çözüm üretebilmesi gibi özelliklerinden dolayı optimizasyon problemleri için daha uygun bir yöntemdir [29-30]. Tablo 3'te optimum değerde olması amaçlanan çıkış değerleri ve değer aralıkları ile belirtilen giriş parametrelerinin değer aralıkları verilmiştir. Optimizasyon algoritması, istenilen sonuç için giriş değerlerini değiştirerek denerken bu değerleri Tablo 3'teki giriş parametreleri için belirlenen aralıklardan seçmektedir. Giriş parametrelerinin değer aralıkları Tablo 2'de verilen değer aralıkları ile aynı seçilmiştir. Çıkış değerlerinin değer aralıkları ise parametrik analiz yöntemi sonucunda elde edilen değişim grafiklerin değer aralıklarına göre belirlenmiştir.

Çok amaçlı optimizasyon yönteminde, optimizasyon işlemine başlanmadan önce belirlenmesi gereken birkaç parametre bulunmaktadır. Bunlar; ağırlık değerleri (Wi), amaç fonksiyonları (Gi) ve maksimum iterasyon sayısıdır. Maliyet fonksiyonları (costi) ve toplam maliyet fonksiyonu (total cost) ise algoritma tarafından hesaplanmaktadır. Ağırlık değerleri (Wi), tasarımcının çıkış değerine verdiği önem derecesini belirtmektedir. Çıkışlar arasından hangisinin optimum değerine daha yakın olması istenirse o çıkış değerinin ağırlık değeri daha yüksek seçilir. Örneğin; tasarlanacak motorun veriminin yüksek olması isteniyorsa ağırlık değeri diğer çıkış değerlerine oranla yüksek ağırlık değeri seçilir. Yapılan optimizasyonda, çıkış değerleri için verilen ağırlık değerleri Tablo 5'te gösterilmiştir. Ayrıca Çok amaçlı optimizasyon yapılırken her çıkış için birer amaç fonksiyonun yazılması gerekmektedir. Amaç fonksiyonun değeri, çıkış değişkeninin değer aralığına göre 1 ile 10 arasında olacak şekilde formülize edilmektedir. RMxprt programında bir çıkışa ait amaç fonksiyonu genel olarak aşağıdaki gibi yazılmaktadır [31]

Tablo 3. Giriş değişkenlerinin değer aralıkları

\begin{tabular}{|c|}
\hline Giriş Parametreleri \\
\hline $\mathbf{1} \leq \mathbf{g} \leq \mathbf{2}$ \\
\hline $\mathbf{3} \leq \mathbf{b s 0} \leq \mathbf{8}$ \\
\hline $\mathbf{2 5} \leq \mathbf{H s} \mathbf{2} \leq \mathbf{3 6}$ \\
\hline $\mathbf{0 . 4} \leq \mathbf{e m b} \leq \mathbf{0 . 9 6}$ \\
\hline $\mathbf{4} \leq \mathbf{l m} \leq \mathbf{8}$ \\
\hline
\end{tabular}

Tablo 4. Çıkış değişkenlerinin değer aralıkları

\begin{tabular}{|c|}
\hline Çıkış Değerleri \\
\hline $1.4 \leq$ stator dişlerindeki akı yoğunluğu $\leq 1.7$ \\
\hline $\mathbf{9 0} \leq$ verim $\leq \mathbf{1 0 0}$ \\
\hline $0 \leq$ vuruntu momenti $\leq \mathbf{1}$ \\
\hline $329 \leq$ çıkış momenti $\leq \mathbf{3 3 1}$ \\
\hline
\end{tabular}

Tablo 5. Seçilen ağırlık değerleri

\begin{tabular}{|c|c|}
\hline Çıkış Değeri & Ăğırlık Değeri (Weight) \\
\hline Stator dişlerindeki akı yoğunluğu (Tesla) & $\left(\mathrm{W}_{1}\right)=1$ \\
\hline Verim $(\%)$ & $\left(\mathrm{W}_{2}\right)=5$ \\
\hline Vuruntu momenti $(\mathrm{Nm})$ & $\left(\mathrm{W}_{3}\right)=1$ \\
\hline Çıkış momenti $(\mathrm{Nm})$ & $\left(\mathrm{W}_{4}\right)=1$ \\
\hline
\end{tabular}

Tablo 6. Amaç fonksiyonları ve optimum amaç değerleri

\begin{tabular}{|c|c|c|}
\hline Çıkış Değeri $\left(\boldsymbol{Y}_{\boldsymbol{i}}\right)$ & Amaç Fonksiyonu $\left(\boldsymbol{G}_{\boldsymbol{i}}\right)$ & Optimum Amaç Değeri $\left(\boldsymbol{G}_{\boldsymbol{i}(\boldsymbol{o p t})}\right)$ \\
\hline Stator dişlerindeki akı yoğunluğu & $G_{2}=1+($ flx.den -1.4$) * 9 / 0.3$ & $G_{1(\text { opt })}=\left.G_{1}\right|_{\text {flx.den=1.4 }}=1$ \\
\hline Verim & $G_{2}=1+($ eff -90$) * 9 / 10$ & $G_{2(\text { opt })}=\left.G_{1}\right|_{\text {eff } f=100}=10$ \\
\hline Vuruntu momenti & $G_{3}=1+(\operatorname{cog} g) * 9$ & $G_{3(\text { opt })}=\left.G_{3}\right|_{\text {cogg=0 }}=1$ \\
\hline Çıkış momenti & $G_{4}=1+($ torq -329$) * 9$ & $G_{4(o p t)}=\left.G_{4}\right|_{\text {torq }=330}=10$ \\
\hline
\end{tabular}




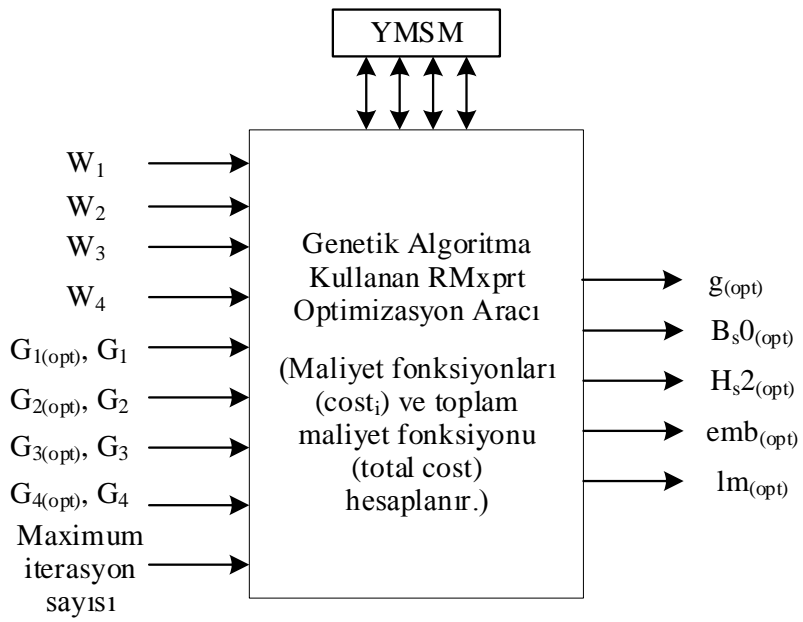

Şekil 5. Çok amaçlı optimizasyon yöntemi

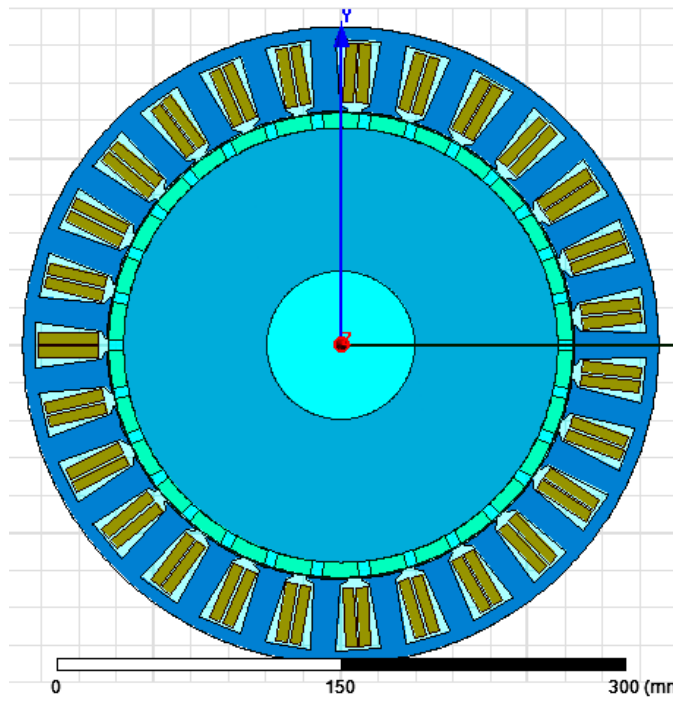

Şekil 6. YMSM'ye ait stator ve rotor geometrisi

$Y_{i(\min )}<Y_{i}<Y_{i(\max )}$ çıkış parametresi değer aralıkları olmak üzere, amaç fonksiyonu;

$$
G_{i}=1+\left(Y_{i}-Y_{i(\min )}\right) * 9 /\left(Y_{i(\max )}-Y_{i(\min )}\right)
$$

İstenilen çıkış değeri, amaç fonksiyonunda yerine yazıldığında elde edilen değere optimum amaç değeri denir ve $G_{i(o p t)}$ olarak ifade edilir.

$$
\left.G_{i(o p t)}=\left.G_{i}\right|_{Y_{i}=Y_{i(o p t)}}=1+\left(Y_{i(o p t)}-Y_{i(\min )}\right) * 9 /\left(Y_{i(\max )}-Y_{i(\min )}\right)\right)
$$

Çıkış değerlerine ait amaç fonksiyonları ve optimum amaç değerleri; Denklem (1) ve Denklem (2) kullanılarak hesaplananmış ve Tablo 6'da verilmiş̧tir Amaç fonksiyonları oluşturulup optimum amaç değerleri belirlendikten sonra algoritma kendi içerisindeki maliyet fonksiyonları kullanmaktadır. Her çıkışa ait maliyet fonksiyonların toplamı da "toplam maliyet fonksiyonu" olarak adlandırılmaktadır. Bir çıkışa ait maliyet fonksiyonu ve toplam maliyet fonksiyonu genel olarak aşağıdaki gibi yazılmaktadır [31].

$$
\begin{aligned}
& \text { cost }_{i}=\left(G_{i}-G_{i(o p t)}\right)^{2} \\
& \text { total cost }=\sum_{i=1}^{n}\left(G_{i}-G_{i(o p t)}\right)^{2}
\end{aligned}
$$

Denklem (3) ve Denklem (4) kullanılarak; Tablo 5 ve Tablo 6'daki değerler aracıllı̆̆ ile elde edilen çıkış parametrelerine ait maliyet fonksiyonları Tablo 7' de verilmiş̧ir.

Toplam maliyet fonksiyonu aşağıdaki denklemde ifade edilmiştir.

$$
\text { total cost }=\left(G_{1}-1\right)^{2} * W_{1}+\left(G_{2}-10\right)^{2} * W_{2}+\left(G_{3}-1\right)^{2} * W_{3}+\left(G_{4}-10\right)^{2} * W_{4}
$$

Optimizasyon algoritması her çıkışa ait maliyet fonksiyonlarını toplayarak elde ettiği toplam maliyet fonksiyonunun değerini minimum yapacak şekilde çalışmaktadır. Algoritma, belirlenen maksimum iterasyon sayısında çalışarak toplam maliyet fonksiyonun minimum olduğu iterasyondaki giriş parametrelerinin değerlerini optimum giriş değerleri olarak belirlemektedir. Beş girişli dört çıkışlı bir YMSM'nin Çok Amaçlı Optimizasyon analizi Şekil 5 'te genel olarak ifade edilmiştir. Optimizasyon algoritması her çıkışa ait maliyet fonksiyonlarını toplayarak elde ettiği toplam maliyet fonksiyonunun değerini minimum yapacak şekilde çalışmaktadır.

Tablo 7. Maliyet fonksiyonları

\begin{tabular}{|c|c|}
\hline Çıkış Değeri & Maliyet Fonksiyonu \\
\hline Stator dişlerindeki akı yoğunluğu & $\operatorname{cost}_{1}=\left(G_{1}-1\right)^{2} * W_{1}$ \\
\hline Verim & $\operatorname{cost}_{2}=\left(G_{2}-10\right)^{2} * W_{2}$ \\
\hline Vuruntu momenti & $\operatorname{cost}_{3}=\left(G_{3}-1\right)^{2} * W_{3}$ \\
\hline Çıkış momenti & $\operatorname{cost}_{4}=\left(G_{4}-10\right)^{2} * W_{4}$ \\
\hline
\end{tabular}


Tablo 8. Parametrelerin algoritma tarafından seçilen değerleri ve analiz sonuçları

\begin{tabular}{|c|c|c|}
\hline & Birim & Algoritma tarafından seçilen değer \\
\hline Hava aralığı $(\mathrm{g})$ & $m m$ & 1.0255 \\
\hline Miknatıs kalınlığı $(\mathrm{lm})$ & $m m$ & 7.967 \\
\hline Mıknatıs doluluk oranı (emb) & - & 0.766 \\
\hline Oluk açıklığı (Bs0) & $m m$ & 7.514 \\
\hline Oluk uzunluğu (Hs2) & $m m$ & 34.584 \\
\hline & Birim & $\mathbf{R M x p r t - A n a l i z ~ S o n u c u ~}$ \\
\hline Verim & $(\%)$ & $\mathbf{9 5 . 0 8}$ \\
\hline Çıkış momenti & $(\mathrm{Nm})$ & $\mathbf{3 2 9 . 6 7 5}$ \\
\hline Vuruntu momenti & $(\mathrm{Nm})$ & $\mathbf{0 . 0 0 0 5 5}$ \\
\hline Stator dişlerindeki akı yoğunluğu & $(\mathrm{T})$ & $\mathbf{1 . 5 7}$ \\
\hline
\end{tabular}

Algoritma, belirlenen maksimum iterasyon sayısında çalışarak toplam maliyet fonksiyonun minimum olduğu iterasyondaki giriş parametrelerinin değerlerini optimum giriş değerleri olarak belirlemektedir. Beş girişli dört çıkışlı bir YMSM'nin Çok Amaçlı Optimizasyon analizi Şekil 5'te genel olarak ifade edilmiştir.

Şekil 5'teki, optimizasyon aracına; ağırlık değerleri $\left(\mathrm{W}_{1}, \mathrm{~W}_{2}, \mathrm{~W}_{3}, \mathrm{~W}_{4}\right)$, amaç fonksiyonları $\left(\mathrm{G}_{1}, \mathrm{G}_{2}, \mathrm{G}_{3}, \mathrm{G}_{4}\right)$, optimum çıkış değerindeki amaç fonksiyonlarının değerleri $\left(\mathrm{G}_{1(\mathrm{opt})}, \mathrm{G}_{2(\mathrm{opt})}, \mathrm{G}_{3(\mathrm{opt})}, \mathrm{G}_{4(\mathrm{opt})}\right)$ ve iterasyon sayıları girilir. Optimizasyon aracı, giriş parametrelerini iterasyon sayısı kadar Tablo 2'de belirtilen aralıklarda değiştirerek; maliyet fonksiyonları (cost $\mathrm{i}_{\mathrm{i}}$ ) ve toplam maliyet fonksiyonunu (total cost) kendi içerisinde hesaplar. Maksimum iterasyon sayısına ulaşıldıktan sonra optimizasyon işlemini bitirir. Optimizasyon aracı her iterasyonda hesapladığı toplam maliyet fonksiyonu değerleri (total cost) içerisinden minimum toplam maliyet değerinin sağlandığı iterasyonu dikkate alarak; bu iterasyonda kullandığı giriş parametre değerlerini optimum giriş değerleri olarak seçmektedir. Analizde optimizasyon algoritması olarak Genetik Algoritma seçilmiştir. Analiz sonuçlarına göre optimizasyon algoritmasının belirlediği parametreler ve bu değerlere bağlı performans değerleri Tablo 8'de verilmiş ve elde edilen tasarıma ait stator ve rotor geometrisi Şekil 6'da gösterilmiştir.

\section{Maxwell 2D Analiz Sonuçları}

ANSYS@Maxwell programının RMxprt bölümünde tasarlanan 27 oluklu-30 kutuplu YMSM programın 2D bölümünde; çıkış momenti, vuruntu momenti ve akı dağılımı açısından analiz edilmiş ve analiz sonuçları ilgili şekillerde gösterilmiştir. Asansör uygulamaları için tasarlanan elektrik motorları performans açısından değerlendirilirken öncelikli olarak önem verilen ölçütlerin; yüksek verim, düşük vuruntu momenti, stator ak1 yoğunluğunun 1.8 Tesla'yı aşmaması ve lineer çıkış momenti (düşük moment dalgalılığı) olarak sıralandığı belirtilmişti. Bu sebeple analiz sonuçlarının önemi belirtilen performans ölçütlerine göre değerlendirilmesi gerekmektedir. Şekil 7'de YMSM' ye ait alan dağılım haritası görülmektedir. Akı yoğunluğu dağılımı motor genelinde ortalama 1,65 Tesla civarındadır. Vuruntu momenti, çıkış momentinin dalgalılığını doğrudan etkilediği için olabildiğince düşük olması istenmektedir. Şekil 9 incelendiğinde vuruntu moment dalgılılığının düşük olduğu görülmektedir. Üretilen çıkış momentinin grafiği ise Şekil 8'de verilmiştir.

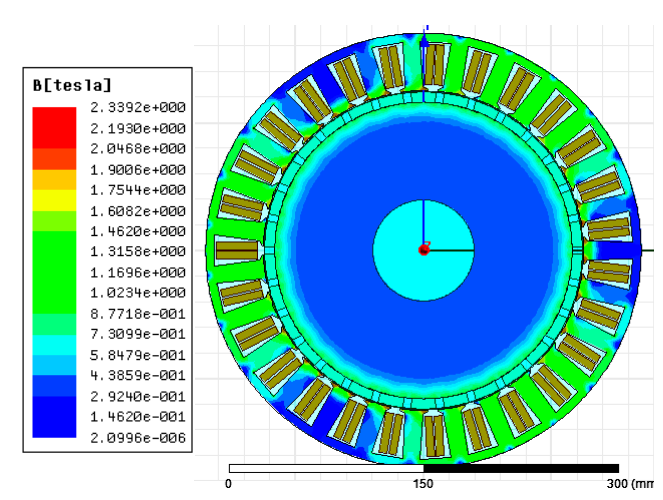

Şekil 7. Manyetik akı yoğunluğu dağılımı

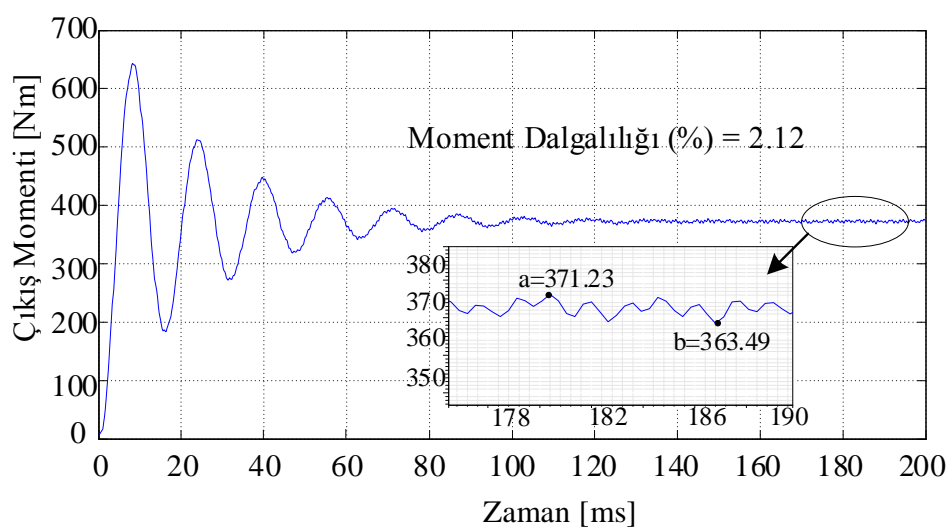

Şekil 8. Çıkış momenti ve moment dalgalılığı analiz sonucu 


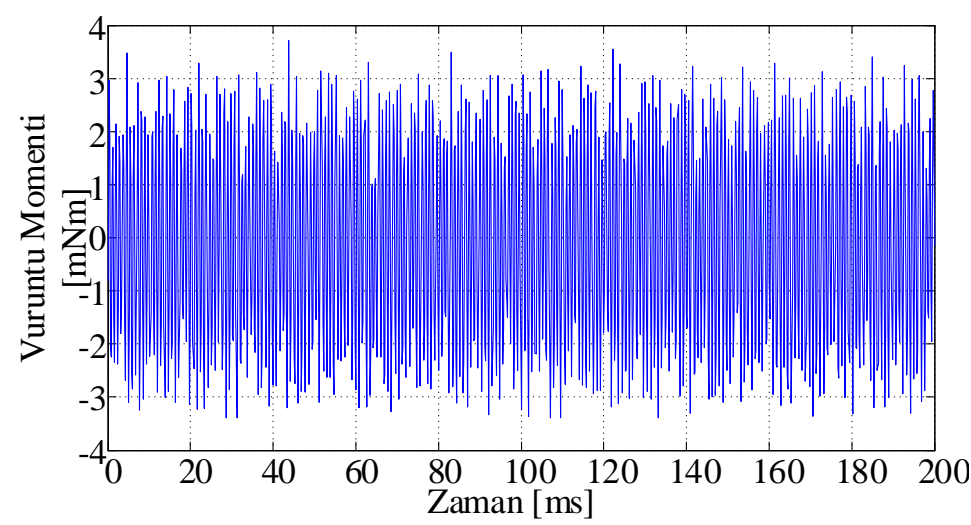

Şekil 9. Vuruntu momenti analiz sonucu

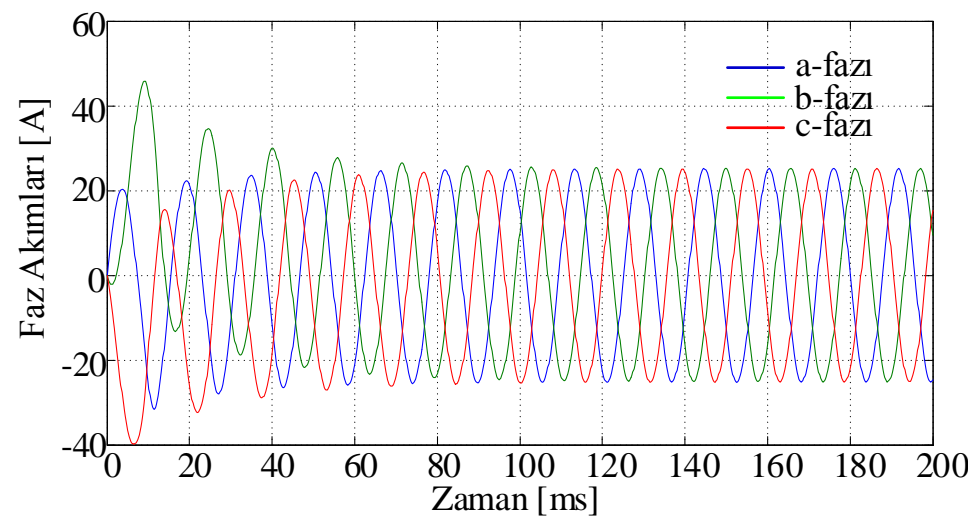

Şekil 10. Faz akımları

Çıkış momentinin moment dalgalılığı $8 \mathrm{Nm}$ civarında çok düşük bir değere sahiptir. Motorun tam yükte çektiği faz akımları Şekil 10'da gösterilmiştir. Tüm analiz sonuçları değerlendirdiğinde performans açısından başarılı bir tasarıma ulaşıldı̆̆ı görülmektedir.

\section{Sonuc}

Bu çalışmada enerji verimliliği bağlamında; asansör uygulamaları için verimliliği oldukça düşük geleneksel dişli kutulu asansör sistemlerine alternatif olarak YMS motor tarafından sürülen yüksek verime sahip dişlisiz asansör sistemi önerilmiştir. $800 \mathrm{~kg} / 10$ kişilik taşıma kapasitesine sahip dişlisiz asansör uygulaması için 27 oluklu 30 kutuplu bir YMS motor tasarlanmıştır. Tasarım sürecinde, performans değerleri üzerinde etkisi önemli olan; hava aralığı, mıknatıs kalınlığı, mıknatıs doluluk oranı, oluk açıklığ1 ve oluk uzunluğu değişkenleri parametrik analiz ve çok amaçlı optimizasyon yöntemi kullanılarak belirlenmiş ve tasarım bu değerler doğrultusunda optimize edilmiştir. Sonuç olarak \% 95.08 oranında verimlilik ile performans açısından iyi bir tasarım elde edilmiştir.

\section{Kaynaklar}

[1] Ficheux RL, Caricchi F, Crescimbini F ve Honorati O. Axial-Flux Permanent-Magnet Motor for Direct-Drive Elevator Systems Without Machine Room. IEEE Transactions on Industry Applications; 2001; 37(6): 1693-1701.

[2] Du ZS ve Lipo TA. High Torque Density and Low Torque Ripple Shaped-Magnet Machines Using Sinusoidal Plus Third Harmonic Shaped Magnets. IEEE Transactions on Industry Applications; May-June 2019; 55(3): 2601-2610.

[3] Guo L, Xia C, Wang H, Wang Z ve Shi T. Improved equivalent magnetic network modeling for analyzing working points of PMs in interior permanent magnet machine, Journal of Magnetism and Magnetic Materials; 2018; 454: 39-50.

[4] Wang JH, Tan FW ve Jin RL. Research on Low-speed Gearless Permanent Magnet Synchronous Motor for Elevator Drive. International Conference on Electrical Machines and Systems; 27-29 Sept. 2005; Nanjing, China. 454-459.

[5] Jahns TM. The Expanding Role of PM Machines in Direct-Drive Applications. Wisconsin Electric Machines and Power Electronics Consortium; 23-25 Oct. 2007; Madison, Wisconsin, USA. 1-6. 
[6] Zhongshu L, Aijun Z, Lie M ve Siyang L. Design of Line-Start Low Speed and High Torque PMSM for Gearless Drive System. International Conference on Electrical Machines and Systems; 20-23 Agust. 2011; Beijing, China. 1-4.

[7] Wang G, Zhang G,Yang D ve Xu D. Robust Low-Cost Control Scheme of Direct-Drive Gearless Traction Machine for Elevators Without a Weight Transducer. IEEE Transactions on Industry Applications; May/Jun. 2012; 48(3): 996-1005.

[8] Wang G, Wang B, Li C ve Xu D. Weight-transducerless control strategy based on active disturbance rejection theory for gearless elevator drives. IET Electric Power Applications; 2017; 11(2): 289-299.

[9] Cicelé S, Albini L, Parasiliti F ve Villani M. Design of a Permanent Magnet Synchronous Motor with Grain Oriented Electrical Steel for Direct-Drive Elevators. 20th International Conference on Electrical Machines; Sept. 2012; Sydney, Australia. 1256-1263.

[10] Yetis H, Boztepeli H, Yasa Y ve Mese E. Comparative design of direct drive PM synchronous motors in gearless elevator systems. 3rd Int. Conf. on Electric Power and Energy Conversion Systems; Oct. 2013; Istanbul, Turkey. 1-5.

[11] Wang G, Xu J, Li T, Zhang G, Zhan H, Ding L ve Xu D. Weight-Transducerless Starting Torque Compensation of Gearless Permanent-Magnet Traction Machine for Direct-Drive Elevators. IEEE Transactions on Industry Applications; Sept. 2014; 61(9): 4594-4604.

[12] Bakhtiarzadeh H, Polat A ve Ergene L T. Design and Analysis of a Permanent Magnet Synchronous Motor for Elevator Applications. Aegean Conference on Electrical Machines and Power Electronics Optimization of Electrical \& Electronic Equipment Conference; May 2017; Brasov, Romania. 293-298.

[13] EN81-1 European Elevator Standards. Brussel, Belgium: CEN, 1998.

[14] Zheng P, Zhao J, Han J, Wang J, Yao Z, ve Liu R. Optimization of the Magnetic Pole Shape of a Permanent-Magnet Synchronous Motor. IEEE Transactions on Industry Applications; Jun. 2007; 43(6): 2531-2533.

[15] Bayındır R, Ocak C ve Topaloğlu İ. Investigation of the Effect of Magnet Thickness on Output Power and Torque of PM BLDC Machines Using Parametric Approach Method. International Conference on Power Engineering, Energy and Electrical Drives; May 2011; Torremolinos, Spain. 1-4.

[16] Wang X, Wang Q, ve Wang Y. Analysis of the Magnetic Field of the Six-phase Disc PMSM and Effect of Permanent Magnet Thickness on the Air Gap Magnetic Field. 2008 World Automation Congress; 28 Sept.-2 Oct. 2008; Hawaii, HI, USA. 1-4.

[17] Ma J, Wu L ve Zhu Z Q. Effect of Magnet Thickness on Electromagnetic Performance of High Speed Permanent Magnet Machines. IEEE International Electric Machines and Drives Conference; 21-24 May 2017; Miami, Florida, USA. 1-7.

[18] Sharkhl S, M, Qazalbash A, Irenjil N T, ve Wills R G, Effect of Slot Configuration and Airgap and Magnet Thicknesses on Rotor Electromagnetic Loss in Surface PM Synchronous Machines. International Conference on Electrical Machines and Systems; 20-23Aug. 2011; Beijing, China. 1-6.

[19] Ayaz M, Tezcan M, Mese E ve Y1lmaz K. Parametric Optimization of Permanent Magnet Synchronous Machines. 6th International Conference on Control Engineering \& Information Technology; 25-27 Oct. 2018; İstanbul, Turkey. 1-6.

[20] Yetis H, Mese E ve Biyikli M. Design and Comparison of Ferrite Based IPM and NdFeB Based SPM Synchronous Motors for Gearless Elevator Systems. International Conference on Electrical Machines; 3-6 Sep.2018; Alexandroupoli, Grecee. 1-7.

[21] Ilka R, Alinejad-Beromi Y ve Yaghobi H. Cogging torque reduction of permanent magnet synchronous motor using multi-objective optimization, Mathematics and Computers in Simulation; 2018; 153: 83-95.

[22] Sudhoff S D, Cale J, Cassimere B ve Swinney M. Genetic Algorithm Based Design of a Permanent Magnet Synchronous Machine. IEEE International Electric Machines and Drives Conference; 15-18 May 2005; San Antonio, TX, USA. 1011-1019.

[23] Cvetkovski G, ve Petkovska L. Efficiency Maximisation in Structural Design Optimisation of Permanent Magnet Synchronous Motor. International Conference on Electrical Machines; Sep. 2008; Vilamoura, Portugal. 1-6.

[24] Duan Y, Harley R G, ve Habetler T G. Multi-objective Design Optimization of Surface Mount Permanent Magnet Machine with Particle Swarm Intelligence. IEEE Swarm Intelligence Symposium; Sep. 21-23 2008; St. Louis MO USA. $1-5$.

[25] Sar1 A, Dubas F, ve Espanet C. Multi-Objective Design Optimization of PMSM for PEM Fuel Cell Air-Circuit with PSO Algorithms. IEEE International Electric Machines and Drives Conference; 3-6 May 2009; Maimi, Florida, USA. 1360-1367.

[26] Lopez C A, Strangas EG. Performance Optimization of PMSM with Torque Ripple Reduction. International Conference on Electrical Machines; Sep. 2018; Alexandroupoli, Grecee. 1-7.

[27] Holland J. H. Adaptation in Natural and Artifcial Systems. Detroit, USA: University of Michigan Press, 1975.

[28] Tufenkci S, Senol B ve Alagoz BB. Stabilization of Fractional Order PID Controllers for Time-Delay Fractional Order Plants by Using Genetic Algorithm. International Conference on Artificial Intelligence and Data Processing; 28-30 Sept. 2018; Malatya, Turkey. 1-6.

[29] Sooriyakumar G, Perryman R ve Dodds SJ. Design Optimisation For Permanent Magnet Synchronous Motors Using Genetic Algorithm. Universities Power Engineering Conference; 31 Aug.-3 Sept. 2010; Cardiff, Wales, UK. 1-6.

[30] Gao J, Dai L ve Zhang W. Improved genetic optimization algorithm with subdomain model for multi-objective optimal design of SPMSM. CES Transactions on Electrical Machines and Systems; March 2018; 2(1): 160-165.

[31] User's guide Maxwell 2D v15. ANSYS, 2016. 